\title{
Why re-purposing HIV drugs Lopinavir/ritonavir to inhibit the SARS-Cov2 protease probably wont work - but re-purposing Ribavirin might since it has a very similar binding site within the RNA-polymerase Sandeep Chakraborty, Gautam Das
}

\section{Letter}

A trial of Lopinavir/Ritonavir in adults hospitalized with severe Covid-19 has not shown significant difference [1]. This is not surprising considering that the HIV aspartic protease - which Lopinavir/Ritonavir inhibit (Table 1) - is quite different from the cysteine proteases in SARS-Cov2.

A review explains this well - 'it is debatable whether HIV protease inhibitors could effectively inhibit the 3-chymotrypsin-like and papain-like proteases of 2019-nCoV. HIV protease belongs to the aspartic protease family, whereas the two coronavirus proteases are from the cysteine protease family. Furthermore, HIV protease inhibitors were specifically optimized to fit the $\mathrm{C} 2$ symmetry in the catalytic site of the HIV protease dimer, but this $\mathrm{C} 2$-symmetric pocket is absent in coronavirus proteases. If HIV protease inhibitors alter host pathways to indirectly interfere with coronavirus infections, their potency remains a concern.' [2].

However, using known structures of the SARS-Cov2, one can dock molecules, and thus re-purpose existing drugs.

\section{Protease inhibitors}

\section{Peptide inhibitors}

A recent pre-print does 'virtual drug screening and high-throughput screening to identify new drug leads that target the COVID-19 virus main protease' [3]. It identifies a small 6 aa peptide that bind to the protease (Table 2).

\section{Small molecule inhibitors}

There is a host of small molecules that bind to the SARS-Cov2 protease (PDB:5R7Y). Table 3 shows the interacting cysteine residues in the active site. There are several such inhibitors.

\section{Ribavirin has a very similar binding site in SARS-Cov2:}

Ribavirin is a guanosine (ribonucleic) analog that inhibits viral replication by inhibition of RNA-dependent RNA polymerase (RdRP) [4]. Recently, the SARS-Cov2 RdRP has been solved (PDBid:6NUR) [5]. This provides a good framework for re-purposing and discovering Ribavirin-like antivirals. Previously, structural studies have shown a similar liganding mechanism in two different viruses (Table 4) using the same two residues (ASP and ASN).

Using the residues from the norovirus (PDB:3SFU), a search for a similar binding site using CLASP [6] gave very good results (Table 5). This was then used to superimpose and dock Ribavirin to the SARS-Cov2 poylmerase (Fig 1) using DOCLASP [7]. Once again, this shows no steric hindrance. The SARS-Cov2 is apo, while the norovirus is holo, i.e. with ligand bound - so there will be some perturbations on binding (Fig 2). The pymol file for superimposition is in SI/super.p1m. A previous study also predicts Ribavirin binding, but the residue numbering is different from the one in the PDB [8]. For example, D651 is actually R651 in the PDB files. Another study has probed the efficacy of other drugs (Alovudine and AZT (an FDA approved HIV/AIDS drug)) [9]. 
Similarly, Remdesivir is a 1-cyano-substituted adenosine nucleotide analogue again influencing the RdRP [10], that protects monkeys from Nipah [11], and has had initial success in treating SARS-Cov2 [12,13]. There are no solved structures with this drug in the PDB database.

\section{Ribavirin dosage caveat}

Adverse events have been associated with high-dose of Ribavirin [14], and consequently antiviral treatment guidelines should be strictly followed [15].

\section{References}

1. Cao B, Wang Y, Wen D, Liu W, Wang J, et al. (0) A trial of Lopinavir-Ritonavir in adults hospitalized with severe Covid-19. New England Journal of Medicine 0: null.

2. Li G, De Clercq E (2020). Therapeutic options for the 2019 novel coronavirus (2019-ncov).

3. Jin Z, Du X, Xu Y, Deng Y, Liu M, et al. (2020) Structure of Mpro from COVID-19 virus and discovery of its inhibitors. bioRxiv .

4. Te HS, Randall G, Jensen DM (2007) Mechanism of action of ribavirin in the treatment of chronic hepatitis c. Gastroenterology \& hepatology 3: 218.

5. Kirchdoerfer RN, Ward AB (2019) Structure of the SARS-Cov nsp12 polymerase bound to nsp7 and nsp8 co-factors. Nature communications 10: 1-9.

6. Chakraborty S, Minda R, Salaye L, Bhattacharjee SK, Rao BJ (2011) Active site detection by spatial conformity and electrostatic analysis - unravelling a proteolytic function in shrimp alkaline phosphatase. PLoS ONE 6: e28470.

7. Chakraborty S (2014) DOCLASP - Docking ligands to target proteins using spatial and electrostatic congruence extracted from a known holoenzyme, and applying simple geometrical transformations [v1; ref status: awaiting peer review,http://f1000r.es/48g ]. F1000Research 3.

8. Elfiky AA (2020) Anti-hcv, nucleotide inhibitors, repurposing against covid-19. Life Sciences : 117477.

9. Ju J, Li X, Kumar S, Jockusch S, Chien M, et al. (2020) Nucleotide analogues as inhibitors of sars-cov polymerase. bioRxiv .

10. Agostini ML, Andres EL, Sims AC, Graham RL, Sheahan TP, et al. (2018) Coronavirus susceptibility to the antiviral remdesivir (GS-5734) is mediated by the viral polymerase and the proofreading exoribonuclease. MBio 9: e00221-18.

11. Lo MK, Feldmann F, Gary JM, Jordan R, Bannister R, et al. (2019) Remdesivir (gs-5734) protects african green monkeys from nipah virus challenge. Science translational medicine 11: eaau9242.

12. Gordon CJ, Tchesnokov EP, Feng JY, Porter DP, Gotte M (2020) The antiviral compound remdesivir potently inhibits RNA-dependent RNA polymerase from Middle East respiratory syndrome coronavirus. Journal of Biological Chemistry : jbc-AC120.

13. Wang M, Cao R, Zhang L, Yang X, Liu J, et al. (2020) Remdesivir and chloroquine effectively inhibit the recently emerged novel coronavirus (2019-ncov) in vitro. Cell research 30: 269-271.

14. Muller MP, Dresser L, Raboud J, McGeer A, Rea E, et al. (2007) Adverse events associated with high-dose ribavirin: Evidence from the toronto outbreak of severe acute respiratory syndrome. Pharmacotherapy: The Journal of Human Pharmacology and Drug Therapy 27: 494-503. 
15. Chong YP, Song JY, Seo YB, Choi JP, Shin HS, et al. (2015) Antiviral treatment guidelines for middle east respiratory syndrome. Infection \& chemotherapy 47: 212-222. 


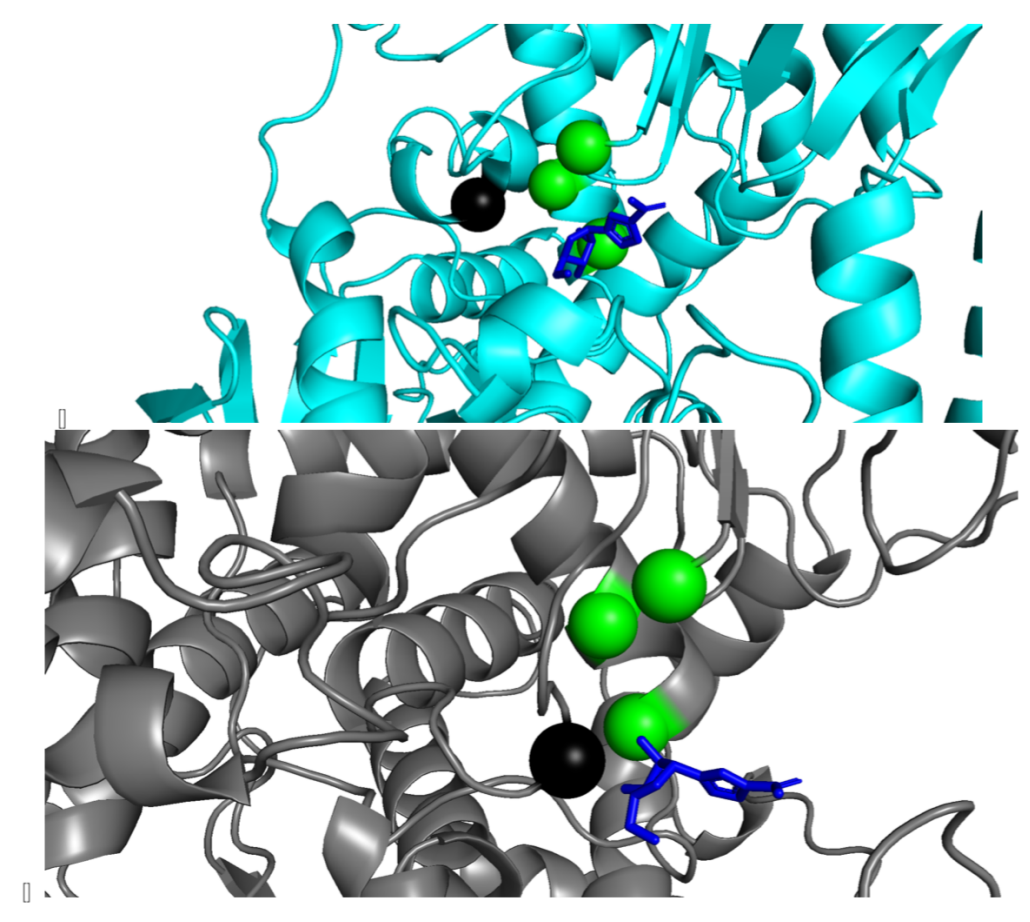

Figure 1: (a) Ribavirin liganded to norovirus (PDB:3SFU) (b) Docking Ribavirin by superimposition of the norovirus (PDB:3SFU) with Ribavirin liganded to the apo SARS-Cov2 (PDB:6NUR) Note, the amino-acids are the same, and their pairwise distance very similar (Table 5).

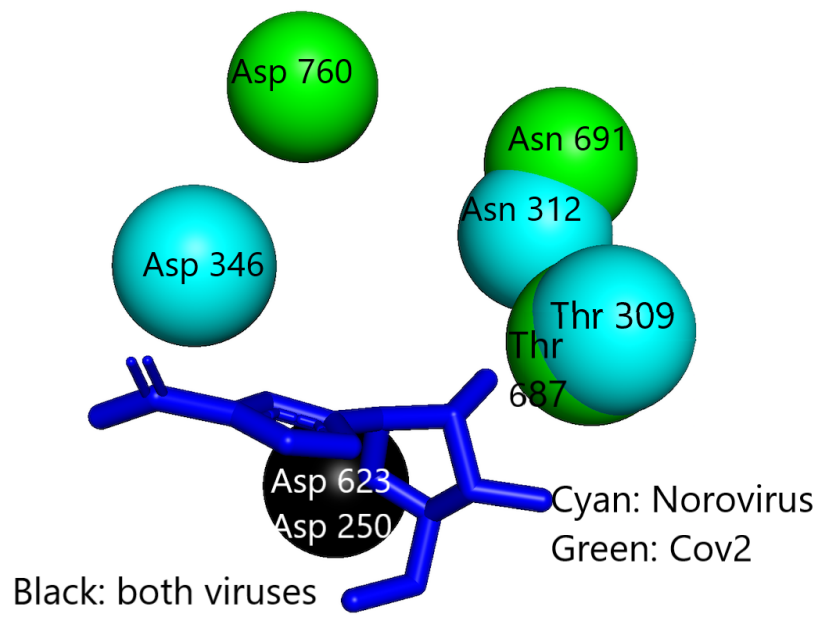

Figure 2: Superimposition of binding residues of Ribavirin: The only difference is Asp346/Asp760 this is because the SARS-Cov2 is in the apo state, with no ligands. C $\alpha$ atoms are shown. 
Table 1: Binding of Ritonavir to the HIV protease - an aspartic protease PDBid:4EYR . Note the ASP amino acid in the catalytic site.

\begin{tabular}{|c|c|c|}
\hline HIV protease atom & Ritonavir atom & Distance \\
\hline ASP29N & C4 CN & 2.7 \\
ASP29N & C4 CN & 2.7 \\
ASP29CB & C4 CC & 2.9 \\
ASP29CB & C4 CC & 2.9 \\
ASN25OD1 & O41 OO & 2.8 \\
ASN25OD1 & O41 OO & 2.8 \\
ASN25ND2 & O41 ON & 2.9 \\
ASN25ND2 & O41 ON & 2.9 \\
ASP30N & N5 NN & 3.1 \\
ASP30N & N5 NN & 3.1 \\
ASP29CA & C4 CC & 3.2 \\
ASP29CA & C4 CC & 3.2 \\
GLY27O & O7 OO & 3.2 \\
GLY27O & O7 OO & 3.2 \\
\hline
\end{tabular}

Table 2: Inhibition of SARS-Cov2 protease using a small peptide inhibitor [3]

\begin{tabular}{|c|c|c|c|c|}
\hline protease & inhibitor & Atom protease & Atom inhibitor & Distance \\
\hline 6LU7A & 6LU7C & GLU/166/O & VAL/3/N & 2.8 \\
6LU7A & 6LU7C & THR/190/O & ALA/2/N & 2.9 \\
6LU7A & 6LU7C & GLN/189/OE1 & LEU/4/N & 2.9 \\
6LU7A & 6LU7C & GLU/166/N & VAL/3/O & 3.0 \\
6LU7A & 6LU7C & $\mathrm{MET/165/CB}$ & $\mathrm{VAL} / 3 / \mathrm{O}$ & 3.2 \\
6LU7A & 6LU7C & $\mathrm{THR} / 190 / \mathrm{O}$ & $\mathrm{ALA} / 2 / \mathrm{CB}$ & 3.3 \\
6LU7A & 6LU7C & $\mathrm{MET} / 165 / \mathrm{CA}$ & $\mathrm{VAL} / 3 / \mathrm{O}$ & 3.3 \\
6LU7A & 6LU7C & $\mathrm{GLN} / 189 / \mathrm{CA}$ & $\mathrm{ALA} / 2 / \mathrm{O}$ & 3.3 \\
6LU7A & 6LU7C & GLN/189/CB & ALA/2/O & 3.4 \\
6LU7A & 6LU7C & GLU/166/O & ALA/2/CA & 3.5 \\
\hline
\end{tabular}


Table 3: Binding of small molecule to the SARS-Cov2 protease - an cysteine protease

\begin{tabular}{|c|c|c|}
\hline SARS-Cov2 protease atom & inhibitor atom & Distance \\
\hline CYS44O & C01/CO & 3.2 \\
CYS44O & C01/CO & 3.2 \\
SER46CA & O04/OC & 3.2 \\
SER46CA & O04/OC & 3.2 \\
SER46CB & O04/OC & 3.3 \\
SER46CB & O04/OC & 3.3 \\
HIS164O & C09/CO & 3.3 \\
HIS164O & C09/CO & 3.3 \\
MET49CE & C10/CC & 3.4 \\
MET49CE & C10/CC & 3.4 \\
MET165CG & C10/CC & 3.5 \\
MET165CG & C10/CC & 3.5 \\
SER46N & O04/ON & 3.4 \\
SER46N & O04/ON & 3.4 \\
\hline
\end{tabular}

Table 4: Residues in contact with Ribavirin in two RNA-polymerases from murine norovirus(PDB:3SFU) and Foot-and-mouth disease virus (PDB:2E9R) This shows the ligand comprises aspartic acid (ASP) and asparagine (ASN) residues, and the search for a similar binding site in the SARS-Cov2 should be guided as such.

\begin{tabular}{|c|c|c|c|}
\hline PDB & virus RNA polymerase & Ribavirin atom & Distance \\
& ASP346OD1 & N3 NO & 2.6 \\
& ASP346OD1 & N3 NO & 2.6 \\
& ASN312ND2 & O2' ON & 2.8 \\
& ASN312ND2 & O2' ON & 2.8 \\
3SFU & ASN312CB & O2' OC & 3.0 \\
& ASN312CB & O2' OC & 3.0 \\
& ASP250OD1 & C5' CO & 3.0 \\
& ASP250OD1 & C5' CO & 3.0 \\
& THR309CA & O2' OC & 3.0 \\
& THR309CA & O2' OC & 3.0 \\
\hline \hline \multirow{6}{*}{ 2E9R } & ASP338OD1 & O2B OO & 2.4 \\
& ASP338OD1 & O2B OO & 2.4 \\
& GLY299N & O3 ON & 2.4 \\
& GLY299N & O3 ON & 2.4 \\
& GLY299CA & O3 OC & 2.6 \\
& GLY299CA & O3 OC & 2.6 \\
& ASP245OD2 & C2' CO & 2.2 \\
& ASP245OD2 & C2' CO & 2.2 \\
& ASN307ND2 & O2' ON & 2.3 \\
& ASN307ND2 & O2' ON & 2.3 \\
& ASP245CG & O2' OC & 2.4 \\
& ASP245CG & O2' OC & 2.4 \\
\hline
\end{tabular}


Table 5: Pairwise distance in residues that bind Ribavirin in norovirus (PDB:3SFU) with cognate binding site in SARS-Cov2 (PDB:6NUR) Distance are in Angstrom $\AA$. Also, note the sequences are also in reasonable order. And the accessibleness of the binding site (Fig 1) - i.e. this binding site is not inside the protein.

\begin{tabular}{|c|c|c|c|c|c|c|c|}
\hline PDB & Residues (a,b,c,d) & ab & ac & ad & bc & bd & cd \\
\hline 3SFU (norovirus) & ASP250,THR309,ASN312,ASP346 & 10.2 & 8.0 & 7.4 & 5.0 & 9.0 & 7.4 \\
6NUR (SARS-Cov2) & ASP623,THR687,ASN691,ASP760 & 9.6 & 9.3 & 9.3 & 5.8 & 10.0 & 6.2 \\
\hline
\end{tabular}

